\title{
Design and Development of a Portable Disinfectant Device
}

\author{
Dhananjay Kumar ${ }^{1} \cdot$ Utkarsha Sonawane $^{1} \cdot$ Mahendra Kumar Gohil $^{1} \cdot$ Ravichand Pol $^{1} \cdot$ Anand S. Patil $^{2}$. \\ Reema Mittal ${ }^{2} \cdot$ Avinash K. Agarwal ${ }^{1,2}$ (])
}

Received: 10 May 2020 / Revised: 9 June 2020 / Accepted: 18 June 2020 / Published online: 24 June 2020

(C) Indian National Academy of Engineering 2020

\begin{abstract}
With over 7 million people infected globally and over 5 lakh deaths reported worldwide by COVID-19 virus, World Health Organization (WHO) has declared it as a pandemic. India is also suffering badly because of the current crisis, with more than 4 lakh people infected and 13000 deaths reported as on 20th June 2020. There is no respite in sight as of now as the numbers continue to increase exponentially with each passing day. The only possible control to the virus is the availability of a vaccine, which will take a few months to be available to masses. Till then, the global economy has to start reopening slowly with several precautionary measures in place as advised by the WHO, such as mandatory wearing of masks in public places, frequent hand washing, practising good personal hygiene, and social distancing. Recently, the government of India (GoI) has also opened its economy with all the precautionary measures in place. Disinfecting of places of work, modes of transport, hospitals, and common areas is emerging as a mammoth challenge. With the objective of arresting the spread of COVID-19 virus and providing an efficient solution to the above problem, a portable disinfectant device is designed. Undertaken as an Industry-academia collaboration, it is a joint initiative between Technopark@iitk (IIT Kanpur Research and Technology Park) and Industry. The novelty of this device lies in its innovative design that combines spraying of sanitising liquid and UV light-based disinfection methodologies. For this, the device uses two separate disinfection systems: (1) the pump-nozzle assembly for spraying the disinfectant, and (2) UV-C radiations to increase the virus kill efficiency.
\end{abstract}

Keywords Covid $\cdot$ Disinfection device $\cdot \mathrm{UV}-\mathrm{C}$ radiations $\cdot$ Spray

\section{Background}

Since December 2019, millions of people have been infected worldwide, by the COVID-19 virus, which originated in Wuhan, China. The COVID-19 virus was declared a global health emergency and a pandemic by the World Health Organization (WHO) in March 2020. The spread of COVID-19 virus is exponentially increasing, leading to tens of thousands of causalities everyday worldwide. The origin of virus in Wuhan, China is still under investigation by various global health and detective agencies. This virus can be transmitted from humans to humans. Furthermore, the virus is also transmitted through tiny airborne droplets

Avinash K. Agarwal

akag@iitk.ac.in

1 Indian Institute of Technology Kanpur, Kanpur 208016, India

2 IIT Kanpur Research and Technology Park (Technopark@ Iitk), Kanpur 208016, India produced, when an infected person coughs, talks, and sneezes. A healthy person gets an infection, when he/she comes in contact or close vicinity with an infected person or contaminated surfaces, and consequently gets contaminated by touching his/her eyes, nose, or mouth. COVID-19 virus can remain active on the surfaces for several days, depending on the texture and material of the contaminated surface. The structure of the COVID-19 virus is explained in detail by Shereen et al. (2020). Various precautionary measures have been advised by the government of India and other health agencies such as Indian Council of Medical Research (ICMR) to prevent further spreading of the deadly virus.

The symptoms of COVID-19 virus infection include fever, tiredness, dry cough and mild respiratory issues, etc. and a few other symptoms include sputum production, headache, haemoptysis, diarrhoea, dyspnoea, and lymphopenia (Ren et al. 2020; Carlos et al. 2020; Rothan and Byrareddy 2020). It might take several days to show symptoms by an infected person, depending on the immunity level of that individual. Some recent observations by ICMR suggest that 
nearly $80 \%$ affected people do not show any symptoms of COVID-19 virus and largely remain asymptomatic (New Economic Times 2020). The virus severely affects older people or people having cardiovascular diseases, diabetes, chronic respiratory diseases, and cancer. These people with compromised immunity have greater chances of getting infected than ordinary healthy people with high immunity. The mortality rate is also found to be relatively much higher in these people with compromised immunity or prevailing health conditions.

A majority of sites across the world have been under lock-down since few months now, in order to slow-down the spread of COVID-19 virus outbreak. Since the vaccine is not available thus far, it is only appropriate to take serious precautions for avoiding its exponential spread, once countries try to start their economic activities. Special attention and efforts are being made by the governments across the world to save human lives. Several disinfectant cabins/tunnels have been installed at public places to disinfect people/ material. Apart from disinfecting people/material, it is also important to sanitise spaces such as malls, office complexes, schools, hospitals, and modes of transport such as airplanes, trains, buses, taxis, metro links etc. For this purpose, handy, compact and low-cost portable devices can prove effective in disinfecting every inch of usable space. The suggested design of the portable device in this paper is a significant improvement over the existing ones as it makes combined use of twin treatments, spraying of a disinfectant liquid and exposure to UV-C (ultraviolet-C) radiations, in order to increase the kill efficiency of the virus.

\section{Compact Design and Technical Challenges}

Various kinds of portable sprayers are already used in agricultural applications for spraying insecticides, pesticides, etc. to aid the growth of plantation/vegetation. These kinds of sprayers can be used for sanitization purposes as well to arrest the spread of COVID-19 virus. Already, such devices are being used in many places in the country using different disinfectant solutions. As an improvement over the existing designs, a new and more effective portable disinfectant device has been developed with twin treatments, using the properties of UV-C radiations while spraying sanitising liquid simultaneously, in order to ensure greater chances of destroying the virus. The device can be used for disinfecting electronic gadgets as well by using the UV-C mode only. The conceptual design of this device is shown in Fig. 1.

There are two main processes involved in this device. One involves using the disinfectant spray through a nozzle. The size of the nozzles ( 20 nos.) ranges from 10 to $20 \mu \mathrm{m}$ diameter and delivers very fine droplets of disinfectant liquid at a high pressure of 2 bar. Any kind of disinfectant liquid can be used depending on the effectiveness and availability, including neutral sanitising liquid as per WHO guidelines or as approved by national regulatory agencies. A schematic showing spray head structure is shown in Fig. 1. One toggle button on the top of the head is used for activating the UV-C radiation lamp, whereas the push button is used for initiating the disinfectant spray.

This portable device consists of the following components.

- Storage tank: for storing the disinfectant liquid (15 L)

- Pump: for pressurising the disinfectant liquid for spray

- UV-C lamp: for generating ultraviolet radiation of $254 \mathrm{~nm}$ wavelength

- Pipes: for connecting the spray head with the disinfectant tank

- Nozzles: for spraying the disinfectant onto the targeted surfaces

- Power source: for powering up the disinfectant pump and UV-C lamp

The above parts are assembled either in the head or in a trolley, which enables it to transport from one place to another, as per the requirement.

Overall structural arrangement of the proposed device is illustrated in Fig. 2, and the tentative technical specifications are given in Table 1. The flow rate of the sanitising liquid from the nozzle would be $<0.2 \mathrm{~L}$ per minute (LPM). The nozzles will be installed in the periphery of UV-C lamp, such that they will not interfere with the UV-C radiations. Both the UV-C radiations and the spray should be targeted on the same area of the surfaces to be disinfected. The overall dimension of the head of this device is $\sim 24$ inch $\times 6$ inch $\times 6$ inch. The weight of the filled device with sanitizer (including trolley and head) would be around $20 \mathrm{~kg}$ and the weight of empty device without sanitizer would be around $7 \mathrm{~kg}$, which makes it portable. The head (nozzle and UV lamp) weighs around $2 \mathrm{~kg}$ and is connected through a long wire/piping to the pump, which is mounted on the trolley. By placing the trolley at a single point, one can disinfect the nearby places and then move the wheel mounted trolley easily to other places. The weight can be further reduced by downsizing the tank capacity from 15 to $5 / 10 \mathrm{~L}$.

The design of handles will be such that it will contain the UV-C source in a box type structure covered by a plexiglass, which prevents any accidental leakage of sanitising liquid, while operating the device. For ensuring the effective disinfection, both UV intensity and residence time should be optimised. The intensity of UV-C will diminish because of ageing of lamp, and fouling of the lamp is possible because of possible deposits. Several other technical challenges associated with this device could be as follows: 


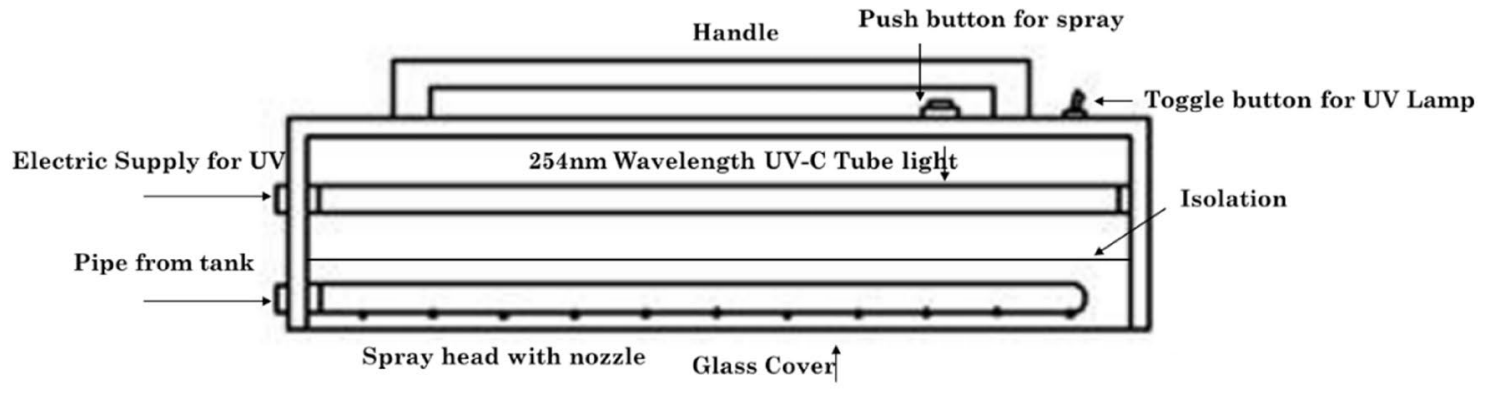

(a) Side View

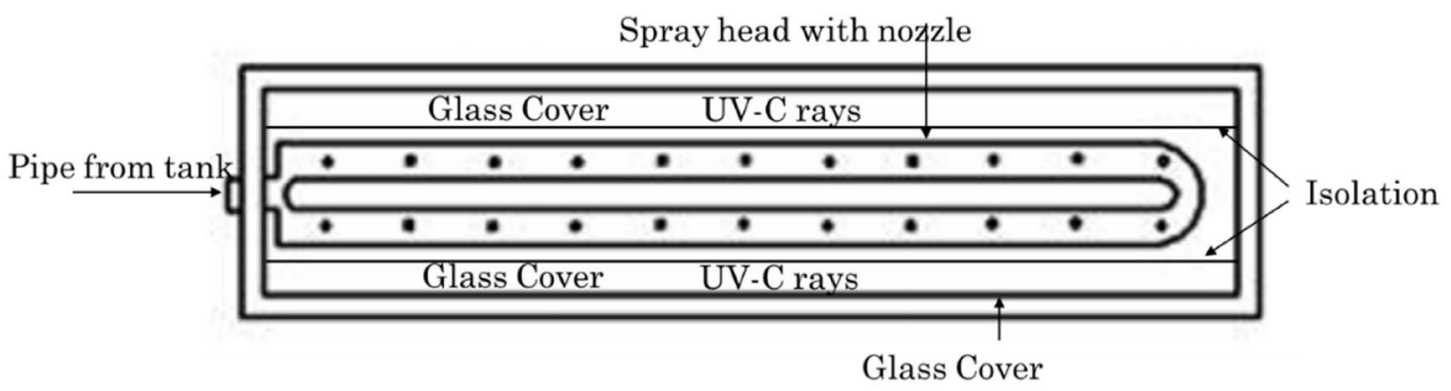

(b) Sectional view consisting nozzles

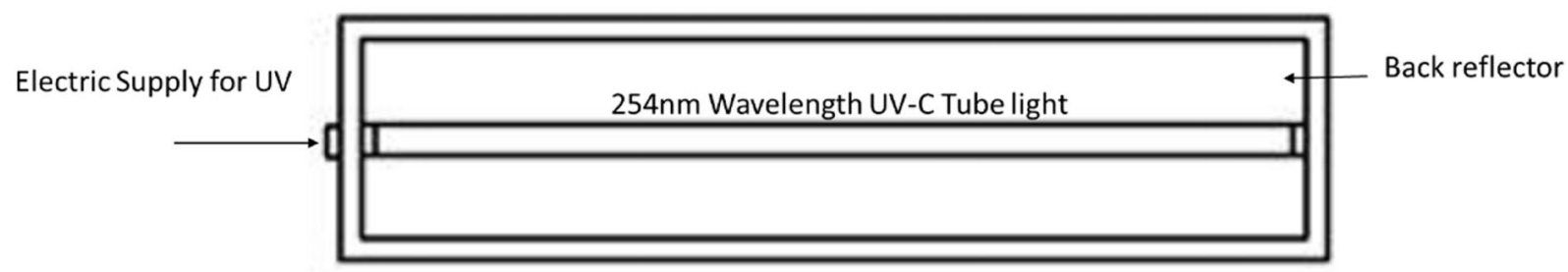

(c) Sectional view consisting UV-C lamp

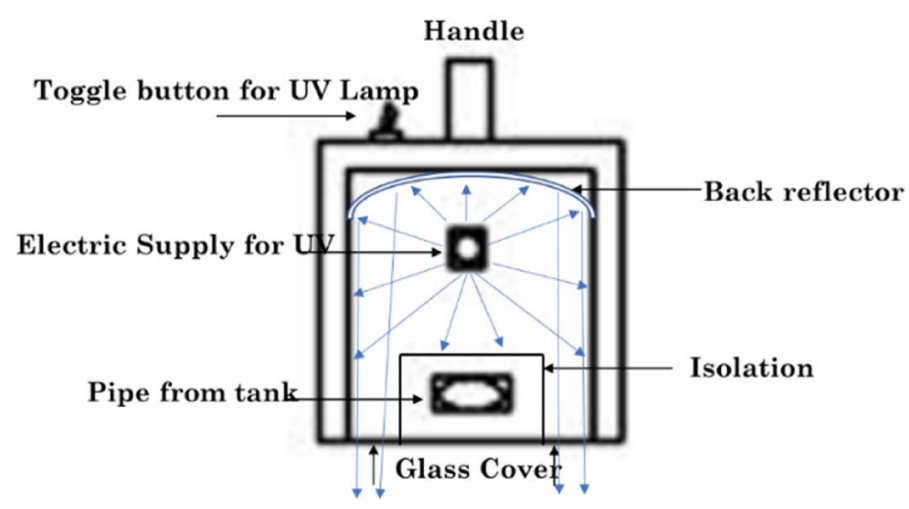

(d) Side view

Fig. 1 Conceptual design showing different views of the head of the portable disinfection device, which accommodates UV-C radiation source and sanitising spray nozzles 


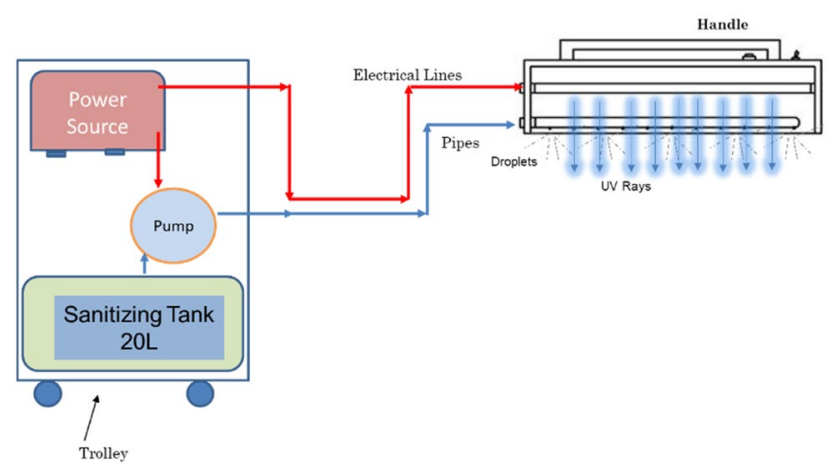

Fig. 2 Overall schematic of the portable disinfectant device

Table 1 Technical specifications of the components

\begin{tabular}{lll}
\hline S. no & Component & Technical specifications \\
\hline 1 & UV-C lamp & Power rating: 15 W, wavelength: 222/254 nm \\
2 & Pump & $100 \mathrm{~W}$, heavy duty pump \\
3 & Nozzle & $10-20 \mu \mathrm{m}$ diameter, 20 nos \\
4 & Power source & AC, if required, a UPS can also be used \\
\hline
\end{tabular}

- There may be interference between disinfectant spray and UV-C chambers, which needs to be taken care-off during the design stage.

- Selection of appropriate spray mechanism including nozzles for hand-held configuration is challenging.

- Geometrical position of the reflector to ensure maximum efficiency of UV-C light exposure to the targeted surface, optimum angle of emitted UV light for the target area, and synchronisation of spraying angle on the target surface.

- Making compact and lightweight design.

- Assembly of both techniques into single device, without compromising stand-alone device efficiency so that each of these can be used in stand-alone mode as well.

\section{Novelty}

This device will be the first of its kind using UV-C radiations and a disinfectant sprayer in a common header in a portable device format. This portable disinfectant device will be able to disinfect the surfaces, wherever used. UV-C radiations of 222-254 nm wavelength have been used for the current application. This device has been specifically developed to disinfect non-living things. However, without using UV-C radiations, it can be equally used for disinfecting living and non-living things. UV-C radiations used in this device could be harmful to the skin and eyes of the living beings, therefore the operator of the device must use spectacles with
UV-C radiation protection and use this device safely. The size of this disinfectant device is quite compact, thereby making it convenient for a person to carry it with ease from one place to another.

\section{Applications}

As India gears up to open its economy, it is now time to exercise more caution and take every possible precaution to prevent the community transmission of COVID-19 virus. Already, the country is witnessing a huge spike in the cases everyday, which are posing serious threat to our economy. Hence, the use of such portable disinfection devices may prove vital in every sector of our economy, as the lockdown is completely lifted and we resume economic activities in full swing. This device has been designed and developed keeping the following applications in mind:

(i) Disinfect public transport such as city buses, passenger trains, airplanes, etc.

(ii) Disinfect hospitals, hotels, office premises, restaurants, malls etc.

(iii) Disinfect shops in vegetable markets.

(iv) Disinfect non-living things, when operated in spray and UV-C mode simultaneously. However, it can be used for living things as well in the spray alone mode, since the 222-254 nm UV-C wavelength may damage the living tissues.

(v) Disinfect shared taxi services, such as Ola, Uber, and personal vehicles frequently by using a further compacted, miniaturised versions of the device.

\section{Summary}

There is an urgent need of a portable disinfectant device to prevent the spread of COVID-19 virus, as the Indian economy opens up gradually. The use of twin treatments of synchronised UV-C radiations and disinfectant spray in a compact head, makes it a suitable, significant and promising contribution for disinfecting places of work, and transport modes such as interiors of bus, aeroplanes, bus-stand, railways, hospitals, hotels, office premises, restaurants, malls etc. Its portable design would make it comfortable to use on a large scale.

\section{References}

Carlos WG, Dela Cruz CS, Cao B, Pasnick S, Jamil S (2020) Novel Wuhan (2019-nCoV) coronavirus. Am J Respir Crit Care Med 201(4):7-8 
News Economic Times (2020). https://economictimes.indiatimes .com/industry/healthcare/biotech/healthcare/no-symptomsin-80-of-covid-cases-raise-concerns/articleshow/75260387. cms?from=mdr. Accessed 21 Apr 2020

Ren LL, Wang YM, Wu ZQ, Xiang ZC, Guo L, Xu T, Jiang YZ, Xiong Y, Li YJ, Li XW, Li H (2020) Identification of a novel coronavirus causing severe pneumonia in human: a descriptive study. Chin Med J 133:1015-1024

Rothan HA, Byrareddy SN (2020) The epidemiology and pathogenesis of coronavirus disease (COVID-19) outbreak. J Autoimmun 109:102433
Shereen MA, Khan S, Kazmi A, Bashir N, Siddique R (2020) COVID19 infection: origin, transmission, and characteristics of human coronaviruses. J Adv Res 24:91-98

Publisher's Note Springer Nature remains neutral with regard to jurisdictional claims in published maps and institutional affiliations. 